\title{
Stability Analysis in Terms of Two Measures
}


This page is intentionally left blank 

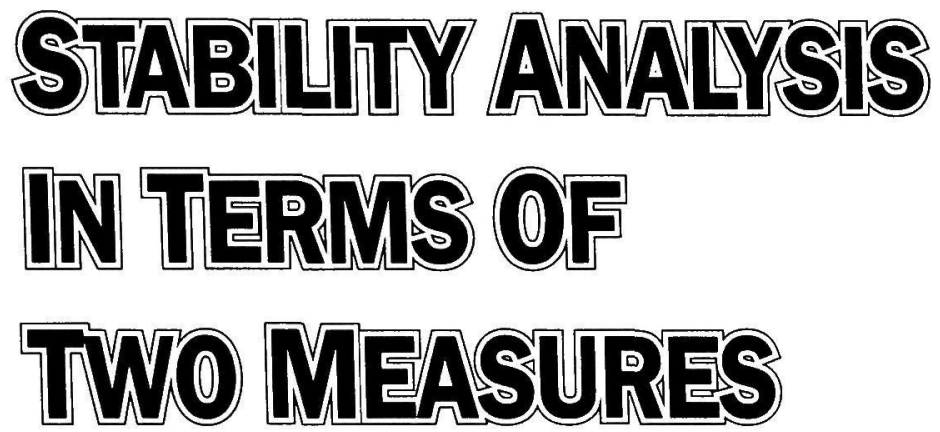

\section{Lakshmikantham}

Department of Applied Mathematics

Florida Institute of Technology

\section{Z. Liu}

Department of Applied Mathematics

University of Waterloo 


\section{Published by}

World Scientific Publishing Co. Pte. Ltd.

P O Box 128, Farrer Road, Singapore 9128

USA office: Suite 1B, 1060 Main Street, River Edge, NJ 07661

UK office: 73 Lynton Mead, Totteridge, London N20 8DH

\section{Library of Congress Cataloging-in-Publication Data}

Lakshmikantham V.

Stability analysis in terms of two measures / by

V. Lakshmikantham, Xinzhi Liu.

p. $\quad \mathrm{cm}$.

Includes bibliographical references and index.

ISBN 9810213891 : $S 48.00$

1. Lyapunov functions. 2. Stability. I. Liu, Xinzhi.

II. Title.

QA871.L246 1993

003'.85'0151535--dc20

93-14063

CIP

Copyright () 1993 by World Scientific Publishing Co. Pte. Ltd.

All rights resenved. This book, or parts thereof, may not be reproduced in any form or by any means, electronic or mechanical, including photocopying, recording or any information storage and retrieval system now known or to be invented, without written permission from the Publisher.

For photocopying of material in this volume, please pay a copying fee through the Copyright Clearance Center, Inc., 27 Congress Street, Salem, MA 01970, USA.

Printed in Singapore by Utopia Press. 


\section{Preface}

The problems of modern society are both complex and multidisciplinary. In spite of the apparent diversity of problems, tools developed in one context are often adaptable to an entirely different situation. As an example, consider the well-known Lyapunov's second method, which has gained increasing significance and has offered decisive impetus for modern development of stability theory of differential equations. A manifest advantage of this technique is that it does not require the knowledge of solutions and therefore has great power in applications to the real world problems from many disciplines.

It is now recognized that the concept of Lyapunov function can be employed to investigate various qualitative and quantitative properties of dynamic systems. Lyapunov 
function serves as a vehicle to transform a given complicated differential system into a relatively simpler system and as a result, it is enough to study the properties of solutions of the simpler system. It is also being realized that the same versatile tools are adaptable to discuss entirely different nonlinear problems, and these effective and fruitful techniques offer an exciting prospect for further advancement.

The concepts of Lyapunov stability have given rise to many new notions that are important in applications. For example, eventual stability, partial stability, relative stability, conditional stability, total stability, and corresponding boundedness and practical stability notions to name a few. Relative to each concept, there exists a sufficient literature parallel to Lyapunov's theory of stability. It is natural to ask whether we can find a notion and develop the corresponding theory which unifies and includes a variety of known concepts of stability in a single set up. The answer is yes and it is the development of stability theory in terms of two measures. It is in this spirit we see the importance of our present monograph. Its aim is to present a systematic account of recent developments in the stability theory in terms of two distinct measures, describe the current state of the art, show the essential unity achieved by wealth of applications, and provide a unified general structure applicable to several nonlinear problems. 
Some important features of the monograph are as follows:

(i) It is the first book that is dedicated to a systematic development of stability criteria in terms of two measures.

(ii) It demonstrates the manifestations of general Lyapunov method in terms of two measures by showing how this effective technique can be adapted to study various apparently diverse nonlinear problems.

(iii) It shows how in the present framework of two measures one can unify criteria of Lyapunov stability, practical stability and boundedness properties, and provides interesting applications of real world problems.

In view of several excellent books on Lyapunov second method, we have not included any material of the usual Lyapunov stability criteria. Since the interplay of the two different measures offers new insights into the stability problem and provides opportunity for new applications, and further advancement, we do hope that this monograph will stimulate further investigation of this fruitful technique of employing two different measures.

The second author was supported in part by a grant from the Natural Science and Engineering Research Council of Canada, which is gratefully acknowledged. 
We are immensely thankful to Dr. B. Kaymakçalan for proofreading and Ms. Donn Harnish for the excellent typing of the manuscript.

\author{
V. Lakshmikantham
}

Xinzhi Liu 


\section{Table of Contents}

Preface .................

1. Basic Theory . . . . . . . . . . . . . . 1

1.0 Introduction . . . . . . . . . . . 1

1.1 Definitions of stability . . . . . . . . . 2

1.2. Basic Lyapunov theory . . . . . . . . . . . 11

1.3 Comparison method . . . . . . . . . . 25

1.4 Converse theorem . . . . . . . . . . . . . 39

1.5 Boundedness and Lagrange stability . . . . . . . 48

1.6 Practical stability . . . . . . . . . . . . 55

$1.7\left(h_{0}, h, M_{0}\right)$-stability $\ldots \ldots \ldots \ldots$

1.8 Invariance principle . . . . . . . . . . . 79

1.9 Notes . . . . . . . . . . . . . . 86

2. Refinements . . . . . . . . . . 89

2.0 Introduction . . . . . . . . . . . . . . 89

2.1 Several Lyapunov functions . . . . . . . . . . 91

2.2 Perturbations of Lyapunov functions . . . . . 107

2.3 Several Lyapunov functions (continued) . . . . . 125

2.4 Method of vector Lyapunov functions . . . . . . . 131

2.5 Perturbed systems . . . . . . . . . . 153 
2.6 Variation of Lyapunov's method . . . . . . . . 169

2.7 Integral stability . . . . . . . . . . . . 180

2.8 Perturbations of Lyapunov functions (continued) . . . . . . . . . . . 192

2.9 Method of higher derivatives . . . . . . . . 200

2.10 Comparison systems . . . . . . . . . . 207

2.11 Cone-valued Lyapunov functions . . . . . . . . . 214

2.12 Notes . . . . . . . . . . . . . . . . . 221

3. Extensions . . . . . . . . . . . . . 223

3.0 Introduction . . . . . . . . . . . . . 223

3.1 Delay differential equations . . . . . . . . . 225

3.2 Implusive differential systems . . . . . . . . . 255

3.3 Stabilization of control systems . . . . . . . . 279

3.4 Impulsive integro-differential systems . . . . . . 296

3.5 Discrete systems . . . . . . . . . . . . . 310

3.6 Random diffferential systems . . . . . . . . . . 319

3.7 Dynamical systems on time scales . . . . . . . 330

3.8 Notes . . . . . . . . . . . . . . . . . 350

4. Applications ... . . . . . . . . . . 353

4.0 Introduction . . . . . . . . . . . . 353

4.1 Holomorphic mechanical systems . . . . . . . 354

4.2 Motion of winged aircraft . . . . . . . . . 361

4.3 Models from economics . . . . . . . . . . . 364

4.4 Motion of a length-varying pendulum . . . . . . 369

4.5 Population models . . . . . . . . . . . . 373

4.6 Angular motion of rigid bodies . . . . . . . . . 380

4.7 Notes . . . . . . . . . . . . . . . . 386

Reference . . . . . . . . . . . . . 387

Index $\ldots \ldots \ldots \ldots \ldots \ldots \ldots \ldots$ 